\title{
Medicare Beneficiaries, Especially Unsubsidized Minorities, Struggle to Pay for Prescription Drugs: Results from the Medicare Current Beneficiary Survey
}

\author{
Meng Li, PhD ${ }^{1,2}$ (1) and Mark Bounthavong, PharmD, PhD $D^{3,4}$
}

'Leonard D. Schaeffer Center for Health Policy \& Economics, University of Southern California, Los Angeles, CA, USA; ${ }^{2}$ Sol Price School of Public Policy, University of Southern California, Los Angeles, CA, USA; ${ }^{3}$ VA Health Economics Resource Center, Menlo Park, CA, USA; ${ }^{4}$ School of Medicine, Stanford University, Palo Alto, CA, USA.

J Gen Intern Med 35(4): 1334-6

DOI: $10.1007 / \mathrm{s} 11606-019-05204-2$

(c) Society of General Internal Medicine 2019

\section{BACKGROUND}

In 2006, Medicare started offering outpatient prescription drug benefit - Part D — with significant cost sharing, including a coverage gap ("donut hole") that required patients to pay the full cost of drugs while in the gap and up to $5 \%$ cost sharing after patients reach the catastrophic coverage limit ( $>5100$ in 2019). Nearly 1 in 10 Part D enrollees had drug spending above the catastrophic coverage threshold in 2015, a quarter of whom did not receive low-income subsidies (LIS) and encountered an average out-of-pocket spending of \$3041 annually. ${ }^{1}$ High cost sharing can lead to cost-coping behaviors such as delaying medication refills, switching to lower-cost alternatives, and spending less on other necessities. Two previous studies on a regional Medicare Advantage (MA) population shortly after Part D went into effect in 2006 found that 26$36 \%$ reported at least one cost-coping behavior. ${ }^{2,3}$ Cost sharing in Part D can create greater financial barriers for minorities and lead to more cost-coping behaviors, as they tend to have lower income than their white counterparts. It is currently unknown if there is any racial/ethnic disparity in prescription drug cost-coping behaviors among Medicare beneficiaries nationally.

\section{OBJECTIVE}

The objective is to examine racial/ethnic disparity in prescription drug cost-coping behaviors in a nationally representative sample of Medicare beneficiaries.

\section{METHODS}

The study population consisted of elderly respondents $(\geq$ 65 years old) to the 2016 Medicare Current Beneficiary

Received June 20, 2019

Accepted July 9, 2019

Published online July 24, 2019
Survey (MCBS). ${ }^{4}$ Participants were asked several questions on their prescription drug cost-coping behaviors, which were mapped into three categories: (1) decreased adherence (take smaller doses, skip doses, delay refilling, not refill); (2) price comparison (ask for generics, compare prices for best price, ask for samples); and (3) financial distress (spend less on other goods to save for prescription drugs).

We estimated the percentage of elderly who reported each type of behaviors by racial/ethnic groups. We conducted multivariable logistic regressions to examine if race/ethnicity was independently associated with those behaviors, adjusting for the individual's age, sex, number of chronic conditions, income, education, prescription drug coverage, MedicareMedicaid dual eligibility, and MA, stratified by receiving LIS (svy, Stata v14, College Station, TX).

\section{FINDINGS}

The 2016 MCBS included 10,629 respondents that were 65 or older, representing over 45 million elderly Medicare enrollees nationally. Among them, $76.9 \%$ were non-Hispanic whites, $8.5 \%$ were non-Hispanic blacks, $7.9 \%$ were Hispanics, and $6.7 \%$ were of other race/ethnicity. A larger proportion of nonHispanic blacks (18.9\%) reported decreased adherence to prescription drugs because of the costs, compared with $14.4 \%$ for other race/ethnicity, $13.9 \%$ for non-Hispanic whites, and $13.2 \%$ for Hispanics (Table 1). Additionally, more non-Hispanic blacks $(9.6 \%)$ reported financial distress, compared with $8.2 \%$ for other race/ethnicity, $6.1 \%$ for Hispanics, and $3.7 \%$ for non-Hispanic whites. Over half of non-Hispanic whites $(52.0 \%)$ reported price-comparing behaviors, compared with $44.3 \%$ for other race/ethnicity, $42.1 \%$ for nonHispanic blacks, and $37.7 \%$ for Hispanics.

After adjusting for individual's sociodemographic characteristics, in the non-LIS population, compared with nonHispanic whites, non-Hispanic blacks had higher odds of reducing adherence (OR 1.49 [95\% CI 1.10-2.01]) and encountering financial distress (OR 2.61 [95\% CI 1.75-3.91]), Hispanics had lower odds of comparing prices (OR 0.72 [95\% CI 0.58-0.89]), and those of other race/ethnicity had lower odds of comparing prices (OR 0.75 [95\% CI 0.58-0.98]) but 
Table 1 Sociodemographic Characteristics and Cost-Coping Behaviors of the Study Population

\begin{tabular}{|c|c|c|c|c|c|}
\hline Race and ethnicity & $\begin{array}{l}\text { All } \\
(N=45,159,815)\end{array}$ & $\begin{array}{l}\text { Non-Hispanic white } \\
(N=34,736,930)\end{array}$ & $\begin{array}{l}\text { Non-Hispanic black } \\
(N=3,843,100)\end{array}$ & $\begin{array}{l}\text { Hispanic } \\
(N=3,567,625)\end{array}$ & $\begin{array}{l}\text { Other } \\
(N=3,012,160)\end{array}$ \\
\hline \multicolumn{6}{|l|}{ Sociodemographics } \\
\hline \multicolumn{6}{|l|}{ Age group $(\%)$} \\
\hline $65-75$ & 59.8 & 59.0 & 62.1 & 60.3 & 65.0 \\
\hline$\geq 75$ & 40.2 & 41.0 & 37.9 & 39.7 & 35.0 \\
\hline Female, \% & 55.0 & 54.6 & 56.7 & 58.6 & 53.1 \\
\hline \multicolumn{6}{|c|}{ Number of chronic conditions $(\%)$} \\
\hline $0-1$ & 23.0 & 23.6 & 18.6 & 18.1 & 27.8 \\
\hline $2-5$ & 63.7 & 63.9 & 66.5 & 64.3 & 56.6 \\
\hline $6+$ & 13.3 & 12.5 & 14.9 & 17.6 & 15.6 \\
\hline \multicolumn{6}{|l|}{ Income $(\%)$} \\
\hline$<\$ 25,000$ & 33.5 & 27.7 & 55.0 & 58.4 & 42.9 \\
\hline$\geq \$ 25,000$ & 66.5 & 72.3 & 45.0 & 41.7 & 57.1 \\
\hline \multicolumn{6}{|l|}{ Education $(\%)$} \\
\hline Less than high school & 15.8 & 10.5 & 30.0 & 49.1 & 19.0 \\
\hline High school or equivalent & 31.6 & 32.8 & 32.0 & 25.6 & 24.1 \\
\hline More than high school & 52.6 & 56.6 & 37.9 & 25.3 & 56.9 \\
\hline Prescription drug coverage (\%) & 90.7 & 90.3 & 92.3 & 95.2 & 88.5 \\
\hline Low-income subsidy (\%) & 14.5 & 8.5 & 34.9 & 39.0 & 28.8 \\
\hline Dual eligible $(\%)$ & 11.9 & 6.7 & 28.0 & 35.6 & 22.9 \\
\hline Medicare Advantage (\%) & 36.8 & 33.9 & 44.1 & 59.0 & 34.5 \\
\hline \multicolumn{6}{|l|}{ Cost-coping behaviors } \\
\hline Any $(\%)$ & 53.0 & 55.1 & 48.6 & 40.9 & 48.6 \\
\hline Decreased adherence $(\%)$ & 14.3 & 13.9 & 18.9 & 13.2 & 14.4 \\
\hline Price comparison $(\%)$ & 49.5 & 52.0 & 42.1 & 37.7 & 44.3 \\
\hline Financial distress $(\%)$ & 4.7 & 3.7 & 9.6 & 6.1 & 8.2 \\
\hline
\end{tabular}

We considered a respondent to have decreased adherence if the respondent answered "Often" or "Sometimes" to any of the following questions: (1) How often took smaller dose of Rx to make medicines last longer; (2) How often skipped doses to make Rx last; (3) How often delayed Rx because of cost; (4) How often not get Rx because of cost. We considered a respondent to engaged in price comparison if the respondent answered "Often" or "Sometimes" to any the following questions: (1) How often ask for generic form of Rx; (2) How often asked for Rx samples from Dr; (3) How often compared prices for best price. We considered a respondent to experience financial distress if the respondent answered "Often" or "Sometimes" to the following question: How often spent less \$ on necessities to save for Rx

higher odds of experiencing financial distress (OR 2.17 [95\% CI 1.06-4.44]) (Table 2). In the LIS population, the racial differences in decreased adherence and financial distress became non-significant. Non-Hispanic blacks and Hispanics had lower odds of comparing prices relative to non-Hispanic whites.

\section{DISCUSSION}

In this nationally representative sample of elderly Medicare beneficiaries, over half reported some prescription drug cost-coping behavior. Unsubsidized minorities, especially non-Hispanic blacks, more often decreased adherence and experienced financial distress from the cost of drugs compared with whites. LIS eliminated these differences in the subsidized population, highlighting its protective effect and the need to expand existing subsidies beyond the current group. We also found that compared with whites, both subsidized and unsubsidized minorities were less likely to engage in cost-saving behaviors that do not adversely affect health outcomes, such as asking for generics and comparing prices. These findings underscored the need for patient

Table 2 Odds Ratios (ORs) with 95\% Confidence Intervals (CIs) from Multivariable Logistic Regressions Examining the Effect of Race and Ethnicity on the Three Types of Cost-Coping Behaviors

\begin{tabular}{llll}
\hline \hline Race and ethnicity & Decreased adherence, OR (95\% CI) & Price comparison, OR (95\% CI) & Financial distress, OR (95\% CI) \\
\hline No low-income subsidy population & Ref & Ref \\
Non-Hispanic white & Ref & $0.82(0.65-1.03)^{* *}$ & $2.61(1.75-3.91)^{* *}$ \\
Non-Hispanic black & $1.49(1.10-2.01)^{* * *}$ & $0.72(0.58-0.89)^{* *}$ & $1.20(0.73-1.95)$ \\
Hispanic & $0.87(0.64-1.19)$ & $0.75(0.58-0.98)^{* *}$ & $2.17(1.06-4.44)^{* *}$ \\
Other & $0.92(0.63-1.34)$ & & Ref \\
Low-income subsidy population & $0.60(0.42-0.86)^{* *}$ & $1.10(0.67-1.83)$ \\
Non-Hispanic white & Ref & $0.51(0.36-0.72)^{* *}$ & $0.68(0.37-1.25)$ \\
Non-Hispanic black & $0.96(0.61-1.49)$ & $0.88(0.60-1.31)$ & $1.42(0.81-2.50)$ \\
Hispanic & $0.70(0.41-1.18)$ & $0.98(0.57-1.69)$ & \\
Other &
\end{tabular}

Covariates adjusted for in the regressions included age, sex, number of chronic disease, income, education, prescription drug coverage, Medicare Advantage, and Medicare-Medicaid dual eligibility

$*$ p-value $<0.1$

**p -value $<0.05$ 
education and empowerment, especially among minorities. Clinicians should also be aware of the financial barriers to the therapies they recommend and how different patients may cope with the costs differently.

Corresponding Author: Meng Li, PhD; Leonard D. Schaeffer Center for Health Policy \& Economics University of Southern California, USCVPD (Suite 312), 635 Downey Way, Los Angeles, CA 90089-333, USA (e-mail: mengli363@gmail.com).

\section{Compliance with Ethical Standards:}

Conflict of Interest: The authors declare that they do not have a conflict of interest.

\section{REFERENCES}

1. Cubanski J, Neuman T, Orgera K, Damico A. No limit: Medicare Part D enrollees exposed to high out-of-pocket drug costs witout a hard cap on spending. Kaiser Family Foundation Issue Brief. 2017.

2. Hsu J, Fung V, Price M, Brand R, Hui R, Fireman B, et al. Medicare Beneficiaries ' Knowledge of Part D and Responses to Drug Costs. JAMA. 2008;299(16):1929-36.

3. Fung V, Reed M, Price M, Brand R, Dow WH, Newhouse JP, et al. Responses to medicare drug costs among near-poor versus subsidized beneficiaries. Health Serv Res. 2013;48(5):1653-68.

4. CMS.gov. Medicare Current Beneficiary Survey (MCBS) [Internet]. [cited 2019 Jun 7]. Available from: https://www.cms.gov/research-statisticsdata-and-systems/research/mcbs/

Publisher's Note Springer Nature remains neutral with regard to jurisdictional claims in published maps and institutional affiliations. 